\title{
Activated Charcoal
}

National Cancer Institute

\section{Source}

National Cancer Institute. Activated Charcoal. NCI Thesaurus. Code C77524.

Carbon that has been treated to create small, low-volume pores that increase the surface area available for adsorption. 